\title{
Industrial Potential of Polyhydroxyalkanoate Bioplastic: A Brief Review
}

\author{
Matthew Bernard*
}

\begin{abstract}
In the international community, human dependence on plastic is increasing. Meanwhile, global petroleum reserves are diminishing. The cost of this demand on petroleum use is not only economic; there are also escalating human and animal health concerns, environmental implications, and the inherent obligation to prepare feasible alternatives in the event that petroleum depletion occurs. While the bioproduct industry is heavily invested in finding fuel substitutes, innovative efforts in other petroleum-dominated industries, such as plastics, may be worthwhile. Fortunately, there are naturally-occurring compounds in bacteria with structures analogous to those currently derived from petroleum. These compounds offer potentially sustainable and healthier alternatives to petroleum. One such compound gaining attention today is polyhydroxyalkanoate (PHA). PHA has several attractive properties as an achievable bioplastic source material, either as a direct substitute or as a blend with petroleum. Genetic modification (GM) may be necessary to achieve adequate yields; accordingly, source and host genetics, agronomic practices, and industry-related technology must be examined in this context. This review will compare properties of petroleum-based to PHA-derived plastics, as well as summarize the obligations of, mechanisms by, and implications with which PHA is being introduced to the plastic industry.
\end{abstract}

Keywords: bioplastic, bioproduct, polyhydroxyalkanoate, biodegradable, GMO

\section{Introduction}

Plastics are end-product materials synthesized primarily of compounds originating from petroleum; however, these finite petroleum reserves are declining. Meanwhile, in a global community of unprecedented population, demand for plastics is increasing. The growing gap between supply and demand has alerted many research groups to explore potential sustainable alternatives to petroleum plastics. At the same time, factors such as political interest, misinformed activism and public interest, and the depth of peer-reviewed research can limit accessibility of pertinent information on the topic and further influence or delay progress in finding feasible plastic alternatives.
Complexities increase when the topic becomes international, particularly when there are health and environmental implications, as is the case with plastics. However, to discuss such a topic effectively demands a fullpicture understanding of the benefits and drawbacks of both the petroleum plastics and potential alternatives, while understanding their interdisciplinary implications.

\section{Fossil Fuels}

Although the exact process by which fossil fuels accrued has not yet been proven, most theories are similar. The remnant material (principally, carbohydrate and protein) of a slow, bacterial decay of plant or animal tissue in an

\footnotetext{
*Department of Food and Bioproduct Sciences, College of Agriculture and Bioresources, University of Saskatchewan, Saskatoon, SK, Canada
} Correspondence: matthew.bernard@usask.ca 
anaerobic environment largely provided the preliminary material; the decay of plankton-type organisms in prehistoric rivers or ocean floors was also a predominant initial source (Wiehe, 2008). The oxygen-free environment arose after silt, sand, and water gradually covered the degraded organic material, subsequently burying it over hundreds of millions of years at sufficient depths and temperatures to facilitate the conversion of the organic decay into a heterogeneous mixture of organic compounds (Hutton et al., 1994). Depending on the combination of plant and animal material decayed, as well as the conditions of the temperature-pressure combination and duration, one of three main types of hydrocarbon reservoirs developed: coal, natural gas, or petroleum (crude oil), the latter having deposited in the smallest relative quantity (U.S. Department of Energy, 2013a; Torrente \& Galán, 2011). It is important to discriminate between oil "resource," which refers to all crude oil thought to exist, and oil "reserve" (or reservoir), which is the quantity that can be recovered within the context of current technologies and economics (Rapier, 2014).

\section{Petroleum}

Petroleum, or "crude," is a term for a broad, naturallyoccurring group of substances comprising many hydrocarbons, referring to their extracted form prior to any processing or modifications. Petroleum, as defined by the Canadian Association of Petroleum Producers (2014), is "a naturally occurring mixture composed predominantly of hydrocarbons in the gaseous, liquid or solid phase." The American Association of Petroleum Geologists defines petroleum as "a thick, flammable, yellow-to-black mixture of gaseous, liquid, and solid hydrocarbons that occurs naturally beneath the earth's surface [and is]...used as a raw material for a wide variety of derivative products" (2012). The Latin origins of the word derive from petra (rock), and oleum (oil) (American Association of Petroleum Geologists, 2012). There are more than one million variations of petroleum molecules predicted, all mixed in a hybrid state of solution and colloid (Wiehe, 2008).

It is important to note "hydrocarbon" in the definitions; understanding molecular structures is

A

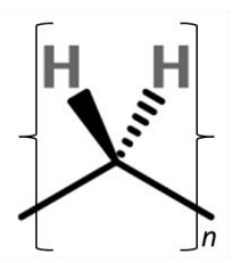

B

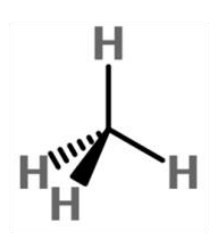

C

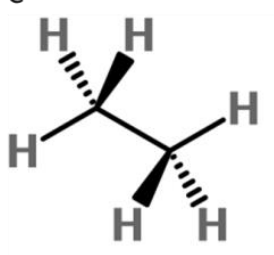

fundamental in the context of feasible petroleum substitutions. Hydrocarbons are "compounds consisting of carbon and hydrogen only," as exemplified in Figure $1 \mathrm{~A}$ (IUPAC, 1997). A linear chain of hydrocarbons adheres to the formula $\mathrm{C}_{n} \mathrm{H}_{2 n+2,}$ and simple hydrocarbons include common compounds such as methane and ethane, natural gases, and octane (prominent in gasoline), with the latter being a light crude oil (Figure 1B-D). A hydrocarbon is the fundamental structure that grants the beneficial stability, consistency, and relative inertness of fossil fuels. Endproduct properties and thus applications of these organic molecules are defined by molecular length, branching, bonding types, chemical modification, and presence of nonorganic elements as some small amounts of sulfur and nitrogen may be present. This high-energy carbon-carbon (C-C) is energetically costly to create; thus, saturated hydrocarbons are not a typical component in a biological system. In the same sense, most organisms were never exposed to these structures throughout their millions of years of evolution and thus lack competent biological processes for their metabolism. Still, the C-C bond is attractive in energy and materials; the high energy of these bonds is ideal to maintain structure in plastics and, in fuels, is released once broken. Atomic bond strength is typically measured in kilocalorie per mole $(\mathrm{kcal} / \mathrm{mol}) ; \mathrm{C}-\mathrm{C}$ bonds require $83 \mathrm{kcal} / \mathrm{mol}$ to break, and for $\mathrm{C}-\mathrm{H}$ bonds, $99 \mathrm{kcal} / \mathrm{mol}$ (Lodish et al., 2000). Degradation of these petroleum compounds can be achieved through thermal treatment which generally results in the release of carbon dioxide and water, but the process is energy-intensive.

Petroleum, the smallest (by reservoir volume) group of fossil fuels, is generally classified into four main groups based on resulting properties of the molecular composition. Light crude is very fluid, clear, volatile, and high-quality and is often used for refining products such as gasoline and plastics. Non-sticky crude is waxy/oily with some adhesiveness, such as paraffin wax. The third group is heavy crude, which is very viscous, dark brown-black in colour, and sticky, as tar, for example. Finally, non-fluid crude is similar to heavy crude, but with little to no viscosity. The classifications are defined by degrees of API gravity, which is an "American Petroleum Institute measure of specific gravity of crude oil or condensate in degrees by chemical

D

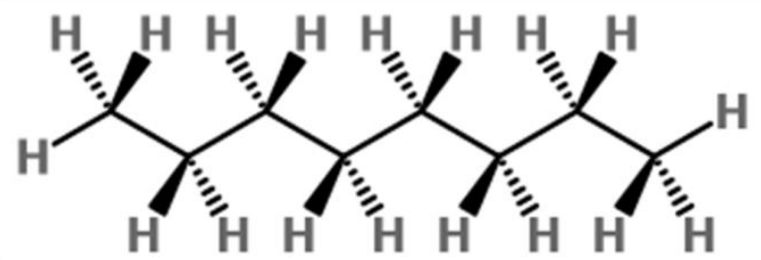

Figure 1. A hydrocarbon unit (A), and common hydrocarbons: Methane (B); Ethane (C); Octane (D). $n$ is number of repeating subunits. 
properties resulting from their molecular constituents," and uses the formula: Degrees API=(141.5/specific gravity)131.5 (United States Environmental Protection Agency, 2013). Crude oil quantity is typically measured in barrel volume, where 1 barrel $=159 \mathrm{~L}$ (International Energy Agency, 2013). Additionally, the final products are relatively straightforward to refine and easy to transport.

\section{Plastics}

Plastics are defined as "a group of materials, either synthetic or naturally occurring, that may be shaped when soft and then hardened to retain the given shape. Plastics are polymers. A polymer is a substance made of many repeating units... poly, meaning many, and meros, meaning parts" (Chemical Heritage Foundation, 2010).

\section{Petroleum Plastics}

After petroleum is extracted, a distillation process separates the crude into fractions based on their boiling points. The light crude is the feedstock from which mostly gasoline and plastics are derived, as well as some other products such as polymers, fertilizers, insecticides, pesticides, solvents, dyes, and other chemicals (Parkash, 2010). The lightest distillate group from light crude, called naphtha, is obtained between distillation temperatures of $37-154^{\circ} \mathrm{C}$ and consists of linear or aromatic hydrocarbons of 5 to 10 carbons (Cs) in length (Parkash, 2010). Cracking, a thermal process used to breakdown these hydrocarbons, results in the monomers such as propylene, butylene, and ethylene (and hydrogen gas, not pictured) (Figure 2), ideal for use as plastics feedstock (PlasticsEurope, 2013a). These various compounds are further catalyzed into one of many types of plastic via polymerization and polycondensation reactions (Figure 3) (PlasticsEurope, 2013a). These polymers often contain double bonds between carbon atoms $(\mathrm{C}=\mathrm{C})$, or even triple bonds $(\mathrm{C} \equiv \mathrm{C})$; the energy involved with these is even greater, reaching 170 and $195 \mathrm{kcal} / \mathrm{mol}$, respectively (Lodish et al., 2000).

The polymerization reactions transform the monomers into various predetermined polymers, which are then developed into the final plastic product. There are hundreds of potential plastic polymers, all belonging to one of two main polymer groups: thermoplastics, which soften once heated then harden after cooled, or thermosets, which cannot soften again after the initial formation (PlasticsEurope, 2013a). Thermoplastics are common, including products using polyethylene, polystyrene, poly(vinyl chloride) (PVC), and polypropylene.

The versatility of conventional plastic is due to its fundamental structure. In its simplest form, petroleum plastic is composed of polymers of hydrocarbons of varying lengths as the backbone and, aside from other carbons, bound with only hydrogen. Other molecular components can be incorporated into these structures, resulting in inorganic polymers thus dictating altered properties and creating a seemingly limitless variety of useful end-products.
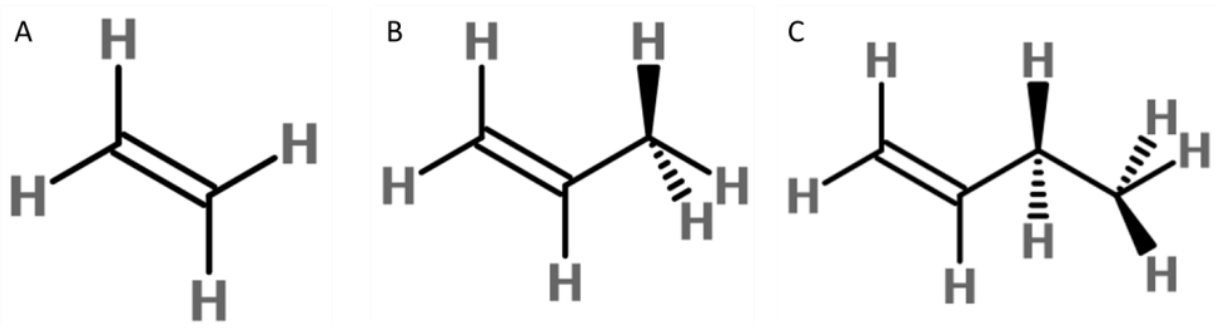

Figure 2. Major products of naphtha cracking: Ethylene (A), Propylene (B), Butylene (C).

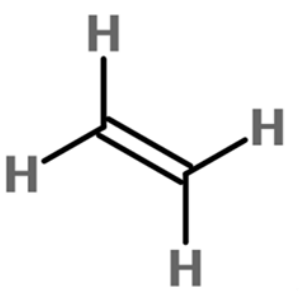

Ethylene

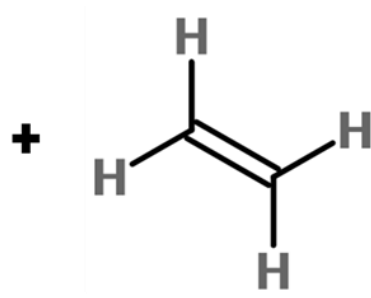

Ethylene

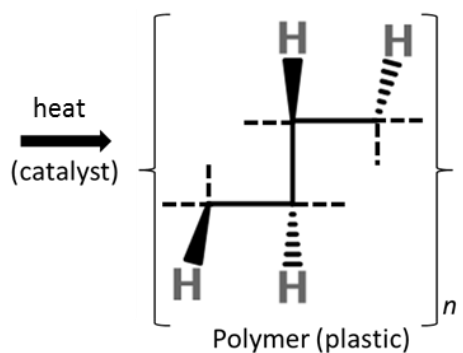

Figure 3. A simplified polymerization reaction of ethylene molecules to produce a polymer, where $n$ is the number of subunits defined by reaction conditions. 
Not surprisingly, petroleum-derived plastics are ubiquitous in the modern world. Petroleum use trends suggest that plastic is not only a huge industry nationally and globally, but also an integral part of modern society (U.S. Department of Energy, 2013b). Globally, plastic production in 2011 reached 280 million tons (PlasticsEurope, 2013b). In Canada in 2012, the chemicals and plastics industries provided employment for more than 162,000 people (Foreign Affairs, Trade and Development Canada, 2013). Eight in ten foreign plastics companies have research and development centres in Canada. Nationally, the plastics industry generates $\$ 72$ billion net profit and is closely linked with extensive and essential industries, such as aerospace, medical, automotive, and telecommunications (Foreign Affairs, Trade and Development Canada, 2013). According to the Canadian Plastics Industry Association, 44\% of all Canadian exports are plastic products (2010). The versatility of petroleum plastic products is conducive to their increasingly widespread use, as is the fundamental structure to their incredible resiliency.

And herein lay several concerns. First, there is concern of supply. Worldwide, 89 million barrels of oil are consumed daily (or 32 billion barrels per year); at this rate, of the proven global crude oil reserves of $\sim 1.5$ trillion barrels, it can be estimated that total reserves will be depleted by 2060 (Organization of the Petroleum Exporting Countries, 2014; International Energy Agency, 2013). Furthermore, world oil demands have been increasing to approach the level of world oil supply, with prices in 2008 reaching record highs (International Energy Agency, 2012). As populations and wealth grow in countries such as China, the demand for light crude does as well, and it is predicted within 40 years they alone will have up to one million additional cars (Rudolf, 2014). It has been predicted that peak oil, the point in history at which petroleum extraction rate has reached the maximum, will fall between 2015 and 2025 (Wiehe, 2008). Moreover, several foreign oil supplies coincide with politically unstable situations, and these conflicts cause much volatility in local supply; even very small changes can cause supply to fluctuate wildly and thus prices (Arian, 2013). The appetite for fossil fuels and petroleum in the $20^{\text {th }}$ century has prompted some to refer to it as the "Petroleum Age," and the more cynical to forecast the coming century as the "Age of Insufficiency" (Wiehe, 2008; Klare, 2007). Regardless of an individual's attitude towards fossil fuel, the current situation is not sustainable over the long term, due to the finite nature of global petroleum stocks; petroleum has a virtual expiration date, albeit unknown. Formation of carbon into petroleum parent material takes $>1,000,000$ years, after which it is released back into the environment and atmosphere in a fraction of the time over a course of 10-100 years; there is a huge net loss of reserves, and net gain of greenhouse gas (GHG) emissions (Narayan, 2006).

GHGs in the atmosphere, such as carbon dioxide $\left(\mathrm{CO}_{2}\right)$, act as a thermal "blanket" to retain surface heat vital for life; still, the abnormal, increasing $\mathrm{CO}_{2}$ concentration is trapping excessive heat, leading to warmer on average conditions (National Aeronautics and Space Administration, 2014b). Thus, a second major issue is pending: as the stockpiles of a material so vital to society are disappearing, the rate at which the environment is changing has increased dramatically (National Aeronautics and Space Administration, 2014a). The current atmospheric $\mathrm{CO}_{2}$ levels are unprecedented compared to the past 650,000 years (National Aeronautics and Space Administration, 2014a). This recent increase of $\mathrm{CO}_{2}$ is the result of huge influxes of petroleum use, causing $\mathrm{CO}_{2}$ release from the relatively short (when compared to the time required to naturally form petroleum stocks) degradation process or from the energy required to recycle plastic waste. Despite being an effective option in some cases, recycling is an energyintensive procedure that consumes petroleum reserves in the form of fuel for the recycling process, thus releasing even more $\mathrm{CO}_{2}$. These $\mathrm{GHG}$ conditions will result in more evaporation and precipitation, warm oceans, and melting glaciers which will increase sea levels, and will change which crops are more competitive as well as ideal cropping locations (National Aeronautics and Space Administration, 2014b). Non-degradable plastics constitute $9.5 \%$ of all waste in Canada (Canadian Plastics Industry Association, 2010). In 2006, petroleum-based products were responsible for 390 million tons of $\mathrm{CO}_{2}$ emissions (Snell \& Peoples, 2009). Furthermore, 1.8 tons of oil create one ton of plastic and 1.9 tons of $\mathrm{CO}_{2}$ (Snell \& Peoples, 2009). Activities related to extracting petroleum directly disrupts many natural habitats; this loss of habitat cascades to affect humans and animals via loss of biodiversity, spread of pathogens, and changing climate that will most noticeably affect food production (Butt et al., 2013). These concerns are not simply restricted to the changing environment.

Petroleum plastic may deteriorate very slowly but, as the Canadian Plastics Industry Association admits, it will never be completely eliminated (2010). Hence, human and animal health becomes compromised in the process. The unnatural end-products of most petroleum plastic may remain completely undegraded or partially degraded. The major concern is that once these small fragments leach out of landfills into groundwater, they eventually reach the beginning of the food chain, attract various toxins, become ingested, and cause either toxicity or mutation of an organism at some point in the food chain - humans included.

Contrary to popular belief, degraded petroleum plastic can be more harmful than the intact waste. "Degradable" is the susceptibility to light and/or chemicals to result in 
partial breakdown; it is not preferred since the incomplete breakdown results in small residual, unnatural pieces of the degraded material in the environment (BASF, 2010). The microscopic fragments can enter into an ecosystem. Any functional groups or inorganic compounds previously bound to the hydrocarbon molecule are freed, and, due to the aliphatic nature of the petroleum, highly-hydrophobic toxic molecules such as insecticides or pesticides can interact and accumulate in these fragments consequently becoming toxin carriers. These toxin-bound fragments may re-enter the food chain with toxin concentrations reaching levels one million times higher than would occur otherwise (Narayan, 2006; BASF, 2010). Well-known examples of such toxins are dichlorodiphenyltrichloroethane (DDT), and also polychlorinated biphenyl (PCB). More recently, a partiallydegradable plastic has emerged termed "oxo-degradable." This type of plastic seemingly breaks down as a true degradable plastic would, yet actually results in tiny polyethylene fragments that remain in the environment (BASF, 2010). Another concern related to animal and human health is imposed by petroleum-derived chemicals whose structures inadvertently mimic endogenous animal hormones, displace them, and thus disrupt regular biological functions such as endocrine signaling (Bienkowski, 2013). The pervasive nature of petroleum plastics suggests that chronic animal exposure to these potentially dangerous chemicals already occurs. For these reasons, initiatives to find alternatives to petroleum plastics are underway.

\section{Bioplastics}

Often, research and media attention on the renewable bioproduct industry is focused specifically on fuel alternatives. This is logical since diminishing fossil fuels supply nearly $80 \%$ of the global energy demands, and it is predicted that the current demand will increase by $56 \%$ by 2040 (U.S. Energy Information Administration, 2013). Currently, though, the renewable energy industry is one of the two fastest-growing industries globally, increasing at a rate of $2.5 \%$ per year (U.S. Energy Information Administration, 2013). By 2015, the demand for biodegradable plastics is estimated to reach 1.1 million tons (Metabolix, 2013a). But in contrast to the large petroleum industry and despite the apparent need for sustainable alternatives, in 2001 Canada had only 133 biotechnology companies which employed 39,140 people, and created total revenue of $\$ 15.3$ billion (Traore, 2003).

Since the first hint of biodegradable, bio-based compounds was identified less than a century ago, the science of biodegradable plastics is relatively young (Lemoigne, 1926). While advancements must be approached pragmatically, there is exciting potential in this growing field of research. This increasing interest in biodegradable biopolymers is in spite of the success of the massive petroleum industry. Biopolymers are typically derived from plant and/or microorganisms, rather than petroleum sources. Once degraded the biopolymers result in oxygen, $\mathrm{CO}_{2}$, and organic matter, with the released energy harnessed by the microorganisms by which they were degraded.

This biodegradation process differs from degradation. "Biodegradable" can be defined in several ways, but complete biodegradation includes some key requirements: the material must be converted to $\mathrm{CO}_{2}$, water, and biomass through microbial assimilation. In a homopolymer, $60 \%$ of the carbon within the product must be converted to $\mathrm{CO}_{2}$ after the biodegradation has occurred in the given timeframe; for blends such as copolymers and heteropolymers, requirements are stricter, as this conversion must reach 90\% (Biodegradable Products Institute, 2012). This conversion must occur in fewer than 180 days at the same rate as natural materials, and within 365 days for a radiolabeled polymer (Narayan, 2006). Furthermore, this must occur in all soil, marine/ocean, compost, aerobic or anaerobic environments, and leave no fragments or residue (Snell \& Peoples, 2009; BASF, 2010). The United States Environmental Protection Agency (EPA) defines the term "biodegrade" as "[to] decompose into more elementary compounds by the action of living organisms, usually referring to microorganisms such as bacteria" (2010). To claim a compound is biodegradable, it is essential that it be assimilated into the environment within a pre-determined time frame (Narayan, 2006). For plant-derived compounds, for example, one growing season is typically recommended, but biodegradability capacity may be dependent upon whether or not a compatible infrastructure is in place that can utilize the specific biodegradable features of the biopolymer. It is important to distinguish between biodegradable and compostable, where the major difference is that compostable products are fabricated of compounds that break down over a very short period (typically, 8 weeks) and the degradation rate matches that of paper (BASF, 2010). In the context of sustainable plastic products, bioplastics (plastics derived from plant sources) are a preferred alternative to petroleum plastics. In the bioplastic lifecycle, $\mathrm{CO}_{2}$ is both created and released within 1-10 years, theoretically resulting in no $\mathrm{CO}_{2}$ net gain or loss (Snell \& Peoples, 2009). Yet, it is crucial to understand both pros and cons of bioplastics before an intentional shift in their favour can begin.

Concerns with bioplastics include influences on the degree to which a material is considered biodegradable. For example, the degree to which the plastic in the final product is crystallized will affect the biodegradation process. Bacterial enzymes tend to have activity upon simpler regions of a substrate and, therefore, the degree of 
biodegradability will decrease with increasing crystallinity (molecular order) of the plastic structure (Tokiwa et al., 2009). Surface area can also affect biodegradability, as reduced surface area will also restrict the ability of a microbe to access the entire quantity of the biodegradable plastic (Tokiwa et al., 2009). Additionally, environmental temperature, $\mathrm{pH}$, moisture, oxygen, nutrient content, and composition also influence the overall process.

Similar to petroleum-based products, there are several variations of biodegradable plastics available. The variations are characterized by their method of biodegradation which results from their molecular composition as outlined by Reddy et al. (2003). One type is developed as a photodegradable compound and includes ultraviolet light-sensitive groups; the degradation process is initiated by sunlight to transform waste into a structure more amenable to microbial degradation. Another type is semi-biodegradable; these are blends of starch-petroleum plastics, with the starch component intended to be targeted by soil microbes, but also results in undegraded residual petroleum particles being released by those organisms. The most attractive option, particularly with regards to a landfill, is a naturally-occurring fermentation product that can be targeted in its entirety (rather than only the connecting bits) by a microbe. Such compounds are polylactides, aliphatic polyesters, polysaccharides, and polyhydroxyalkanoates.

\section{Polyhydroxyalkanoate (PHA)}

An ideal biodegradable biopolymer is polyhydroxyalkanoate (PHA). Presence of a derivative of PHA was first documented in the bacterium Bacillus megaterium (Lemoigne, 1926). The molecule received little attention until several decades later (Williamson \& Wilkinson, 1958). At that time, it was noted that bacteria could naturally degrade $\mathrm{PHA}_{\text {; }}$ thus, the biopolymer was identified early as an ideal alternative source of bioplastic (Chowdhury, 1963; Baptist, 1962). PHA is naturally synthesized, easy to recover, and produced from low-cost feedstocks.

\section{PHA Structure, Function and Mechanism}

PHA (Figure $4 \mathrm{~A}$ ) is a versatile, naturally occurring, lipid-like water-insoluble polyester molecule that can be found in more than 75 genera of prokaryotes and archaea (Huang \& Reusch, 1996; Reddy, 2003; Rehm, 2003). Inside the living cell, PHA acts as an intracellular, granular energy storage reserve; its synthesis and accumulation is triggered by unfavourable growth conditions (Smet et al., 1983). It is the sugar- or lipid-derived, microbial fermentation polyester product of PHA synthases. This linear polyester consists of $10^{3}-10^{4}$ monomer subunits and is usually $0.2-0.5 \mathrm{~mm}$ in length; in each of the most basic subunits (Figure ${ }_{4} \mathrm{~A}$ ), alkyl groups are found in the R-position of the $\mathrm{C}-3$ carbon and range from 1-14 carbons in length (Rehm, 2003). Its candidacy as a petroleum substitute arises from physical and chemical similarities, but in contrast to the petroleum hydrocarbon subunit PHA is derived from an ester group (Figure ${ }_{4} \mathrm{C}$ ):

PHA, as it pertains to bioplastic, is commonly discussed in two forms. The first is a linear, high-molecular weight polyester of 60,000 Daltons ( $\mathrm{Da}$ ) found in Grampositive and Gram-negative bacteria, as well as in some archaea (Reddy, 2003). Up to 150 different monomer variants of PHA have been identified, and the compositional variation is the result of carbon sources available to the source organism, as well as from endogenous pathways in the cell in which it is synthesized where both factors add variation of the R-group (Narayan, 2006; Rehm, 2003). The high-molecular weight PHA is the energy storage form accumulated in nutrient-deficient conditions. The second form is the simplest monomer "building block" form of PHA called polyhydroxybutyrate (PHB), a low molecular weight $(15,000 \mathrm{Da})$ molecule (Figure $4 \mathrm{~B})$. This form is found in many prokaryotes and confers the ideal versatility typically desired of a petroleum replacement (Snell \& Peoples, 2009; Narayan, 2006). This low-weight form is a non-storage PHA and is believed to function in calcium channels, DNA transport, or protection of other macromolecules in the cell (Reddy, 2002). The isolated compound acts as a thermoplastic and can thus be melt-processed for extrusion in a fashion similar to
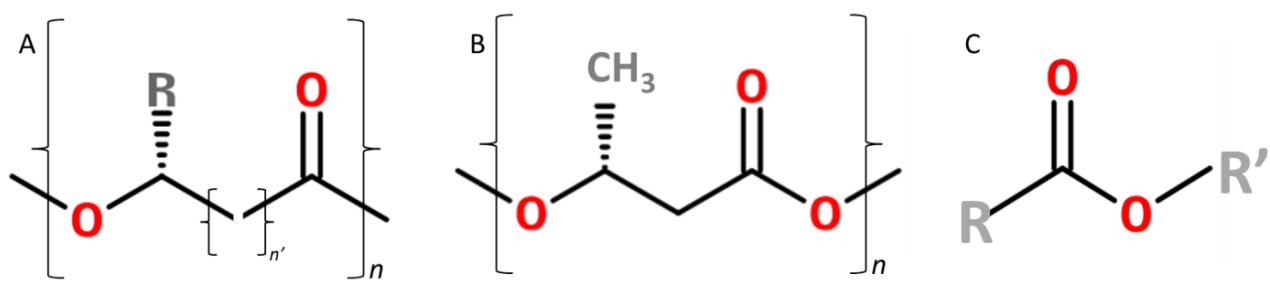

Figure 4. Polyhydroxyalkanoate (PHA) (A); Polyhydroxybutyrate (PHB) (B); An ester (C). $n$ is number of subunits, $n^{\prime}$ is number of carbons within subunit, $R$ and $R^{\prime}$ are alkyl groups. 
petroleum-derived plastics. Energetically, these biological molecules are ideal substitutes for petroleum, as $\mathrm{C}-\mathrm{O}$ bonds require $84 \mathrm{kcal} / \mathrm{mol}$ to break, and $\mathrm{C}=\mathrm{O}$ needs $147 \mathrm{kcal} / \mathrm{mol}$ (Lodish et al., 2000).

Diversity of PHA and its utility arise from not only the fundamental structure, but also its capacity to be assembled into heteropolymers. For example, short-chain PHA (SPHA) polymers with no more than 5 carbon atoms in the R-group are brittle and rigid bioplastics. Those with 6-14 carbon atoms are medium-chain PHAs (mPHA); these are semi-crystalline thermoplastic elastomeres and have sticky properties (Suriyamongkol et al,. 2007). PHA ester intermediates can be used for blends for heteropolymers comprised of only biopolymers with unique properties, or for direct integration with petroleum plastics, meanwhile retaining the original function of the petroleum being replaced and also reducing the overall demand for petroleum plastic synthesis (Suriyamongkol et al., 2007). PHA can also be mixed with other bio-based plasticizers, such as glyceroltriacetate or diethyl succinate, to achieve desirable and sustainable blends (Narayan, 2006).

PHA differs most importantly from petroleum plastics in its speed and degree of biodegradability although the end products are mostly $\mathrm{CO}_{2}$ and water (Suriyamongkol et al., 2007). Notably, PHA is biodegradable in all living systems (Snell \& Peoples, 2009). A huge advantage in this process is that the carbon released is already part of the current carbon cycle (versus a sudden release from ancient petroleum stockpiles); thus, no net gain or loss is produced. This advantage comes from its fundamental structures (Figure 4). As a polymer, it acts as a petroleum-based plastic, but in place of carbon chains saturated with hydrogen, PHA contains one or several functional groups chemical groups that are free to undergo chemical reactions. Aside from enhancing the potential functional versatility of the molecule, these groups are used to initiate the biodegradation process once stimulated by an environmental trigger (Narayan, 2006).

\section{PHA Sources, Biosynthesis, and Degradation}

There are several routes by which PHA can be obtained and utilized. As Snell and Peoples outline, industrial production of PHA would require a two-step process: accumulation of PHA followed by its extraction (2009). Since PHA is naturally occurring in over 300 bacteria, there are several starting points. Ideally, the accumulation process is via a microbial aerobic fermentation process using cellulosic material, sugar, or even vegetable oil as the carbon source. Other studies have shown high accumulations of PHA in organisms existing in symbiotic associations, such as in Rhizobia spp., a prokaryote in symbiosis with eukaryotic legumes (Suriyamongkol et al., 2007). Others, such as Ralstonia eutropha, have been shown to contain as much as
90\% dry weight (dwt) of the cell as PHA (Suriyamongkol et al., 2007). Ideal transgenic eukaryote hosts are $C_{4}$ plants that convert $\mathrm{CO}_{2}$ to biomass most efficiently. Several plants have shown increased PHA accumulation, after agronomicrelated GM enhancements. Examples include Brassica napus once the 12-hydroxylase promoter activity is upregulated, Panicum virgatum after increasing their resiliency, and Arabidopsis which has produced the highest PHA yield of any plants designed for PHA accumulation (Houmiel et al., 1999; Somleva et al., 2008; NewsRX, 2013). Brassica napus, Panicum virgatum, and Arabidopsis have accumulated $7.7 \%, 3.7 \%$, and $14 \%$ dwt PHA content, respectively (Houmiel et al., 1999; Somleva et al., 2008; NewsRX, 2013). It is important to note that while eukaryotes have a relatively lower \%dwt production of PHA, their overall biomass is substantially greater.

After the presence of PHA is confirmed in an organism, the purified compound must be obtained. Several extraction processes exist for obtaining PHA from the source. One method is to use a solvent to extract the lipophilic PHA from the cells. After first lysing the host cells by some mechanism, hot methanol reflux is performed to remove lipophilic material from cells; PHA is solubilized in chloroform, followed by evaporation of the solvent and precipitation of the PHA by methanol (Suriyamongkol et al., 2007). Other options include solvent extraction, chemical or enzymatic treatment whereby the material is digested to remove all undesired material such as proteins and lipids, followed by filtration and centrifugation to collect the PHA, but most protocols are several variations on the same basic principles (Kunasundari \& Sudesh, 2011).

To date, naturally-occurring PHA is synthesized in select bacteria. So far, unfortunately, these species have relatively lower growth temperatures, longer generation times, contain endogenous PHA-degradation pathways, and can be challenging to lyse for the purposes of extracting the compounds of interest (Reddy, 2003). Ideally, these problems would be resolved while maintaining high levels of PHA accumulation. This idea has prompted research in the genetics underlying PHA biosynthesis.

There are three genes required for PHA production, and their exploitation could enhance PHA production for feasible industrial-scale production. phaA is a gene encoding for $b$-ketothiolase, an enzyme that converts two acetyl-CoA molecules into acetoacetyl-CoA. The second, phaB, codes for acetoacetyl-CoA reductase, an enzyme that converts acetoacetyl-CoA to R-3-hydroxybutyryl. Thirdly, phaC codes for PHA synthase, which polymerizes R-3hydroxybutyryl into longer polymers (Suriyamongkol et al., 2007; Snell \& Peoples, 2007). Depending on the organism, some or all of these genes can be found in the same operon (or, cluster of associated genes). Using molecular techniques, however, genetic markers could be developed for early selection of those organisms with higher PHA- 
producing capability. Another option is to develop a recombinant variant with genetic enhancements to gain the benefits of both the PHA production, while achieving faster and easier recovery. The GM enhancements would include the phaABC operon, and perhaps other genes to enhance traits advantageous to the PHA production process. For example, the $E$. coli has higher growth temperatures, faster generation times, better extraction properties and has no PHA-degradation pathways; a phaABC-recombinant strain would include all these benefits while now being capable of PHA biosynthesis (Reddy, 2003). Plants are slower to grow than bacteria, but biomass yields are much higher with added benefits of potential co-products. In a plant, the phaABC operon could be introduced along with other traits, such as drought-tolerance, to establish a competitive, PHAproducing transgenic crop. Regardless of the host, the goal is to combine the beneficial traits of both the source and host organisms. Recombinant strains in either bacteria or plants are realistic options; the decision would be dependent on the economics and regulations, as well as facilities and space available.

Genetic requirements in addition to exploiting the phaABC operon may be necessary in order to achieve industrial scale production of $\mathrm{PHA}$, if it is to be a feasible alternative to petroleum. Genetic modifications have been attempted in PHA-producing plants with some success in altering certain traits. For example, input traits such as increasing drought tolerance and biomass yield would alleviate some of the current agronomic consumption of petroleum fuel, while maximizing the actual PHA compound of interest in the land area available; moreover, it could be optimized for production on low-quality soil which typically remains absent of food, feed, or biomass crop altogether. Output traits, such as increasing enzymatic activity to improve cellulose hydrolysis, have been beneficial (Sticklen, 2008). PHA localization and quantities differ amongst organelles; significant levels have been observed in peroxisomes, plastids, cytosol, and mitochondria. However, van Veilen and Poirier have found the plastid to naturally contain highest levels (2008). This is probably due to high acetyl-CoA and carbon content (components necessary for PHA synthesis) since plastids are a primary site of plant fatty acid biosynthesis. To increase yields further, the plastid-targeting signal can be included phaABC operon, with the intention of upregulating their activity at their most active site, to result in the most efficient accumulation of PHA (Somleva et al., 2008). Using Agrobacterium tumefaciens, transgenic Panicum virgatum yields have increased $30 \%$ higher than the parent plants, with yearly increases of 1-7\%; maize yearly biomass yield increases are no higher than 1.2\% (McLaughlin \& Kszos, 2005). Lastly, high levels of PHA in a photosynthetic host cell may damage chloroplast, so it may be necessary to enhance chloroplast production and accumulation to ensure adequate photosynthesis occurs (Suriyamongkol et al., 2007). Preferably, a host organism for bioplastic PHA synthesis would yield high levels of the compound, flourish in an environment with low inputs, require little modification to existing equipment and infrastructure, and be economically feasible.

Panicum virgatum, commonly known as switchgrass, has received much attention as a realistic transgenic host for harvesting PHA. Switchgrass is a native prairie cereal. Here, it thrives not only with low moisture and low chemical inputs, but also on marginal land unsuitable for food/feed crops, increasing the productivity potential of the land (McLaughlin \& Kszos, 2005). It could be harvested with conventional machinery, stored as bales for up to 6 months (longer, if refined to pellets), and requires very little management. Blight Native Seeds Ltd. in Oakville, Manitoba, is an example of realistic switchgrass production, albeit for biofuel purposes, but assuming the viability of the plant is unaffected, a PHA source crop would be operated in a similar fashion. The perennial crop has thrived for at least 9 years after the initial harvest, and with minimal maintenance (Redekop, 2006). Maximum switchgrass dry biomass yields have been documented at levels achieving 10-15 tons/acre; for context, typical springwheat production in Saskatchewan is 0.6-1.8 tons/acre (Snell \& Peoples, 2009; Government of Saskatchewan, 2009). Production efficiencies suggest that 1 million tons of switchgrass biomass could produce 100,000 tons of PHA, and cogenerate 62 million gallons of ethanol. Studies by McLaughlin and Kszos endorse the efficiency of switchgrass when compared with other plants that could be used for the same purpose, as biomass yields double those of maize (2005). Finally, based on \$0.98USD/bushel switchgrass, McLaughlin and Kszos propose that 3.2 million acres of American cropland could more economically support switchgrass than current crops, providing a possible \$1 billion net gain, a return on investment (ROI) of 1000:1 (2005). Research and development have reached field trial stage in this crop (Metabolix, Inc., 2008).

PHA has been found to be degraded by many different genera and species of bacteria and fungi, both aerobically and anaerobically (Tokiwa et al., 2009). Some examples include Acidovorax faecalis, Aspergillus fumigatus, Pseudomonas lemoigne, and Variovorax paradoxus from the soil, Alcaligenes faecalis, Pseudomonas sp., and Illyobacter delafieldi from anaerobic sludge, and Comamonas testosterone and Pseudomonas stutzeri from both fresh and sea water sources, and other Actinomadura, Aspergillus sp., Microbispora, Saccharomonospor, Streptomyces, and Thermoactinomyces spp (Tokiwa et al., 2009). The triggers are specific interactions between the PHA molecule and a microbial hydrolytic influence. First, a degradative enzyme produced by one of these microbes must bind to the bioplastic polymer; then, its hydrolytic cleaving action can 
interact with the functional groups of the PHA as it breaks the polymer to lower weight oligomers, then further into dimers, monomers, and is eventually mineralized by the microbes (Tokiwa et al., 2009). The microbes utilize the minerals and energy, while $\mathrm{CO}_{2}$ and $\mathrm{H}_{2} \mathrm{O}$ are released back into the environment (Sudesh et al., 2000). Catalytic additives or a built-in susceptibility to oxidation in a PHA bioplastic could be engineered and act as deliberate triggers. The hydrolytic cleavage action and complete degradation process of the PHA depolymerases are quite short, taking only 3-9 months (Suriyamongkol et al., 2007).

\section{Health, Environmental and Industrial Implications}

The long-term impact of PHA bioplastic is attractive. Ingestion of PHA by mammals has been studied, with no harmful effects observed (Forni et al., 1999a; Forni et al., 1999b). In microorganisms, neither the polymer nor its lytic intermediates are toxic. As Suriyamongkol et al. indicate, PHA depolymerase, an enzyme endogenous to many microorganisms, degrades the molecule into 3-hydroxyacid (2007). This has no effect on animals, as their systems naturally contain this molecule and thus have mechanisms for its metabolism.

As some host organisms in which PHA can be synthesized are strictly biomass crops, there is less concern of GM in the food system, regardless of whether or not GM crops have inherent human risk. Furthermore, there is potential to render poor quality, unproductive land useable, depending on the type of GM introduced to the host. Or, if grown on fertile soil, it can offer another option in a producer's crop rotation, and potentially contribute agronomically in this sense. These ideas have been examined previously, and encouraging evidence exists (Huang et al., 2002).

If bioplastic crops were to be grown on such a large scale, the industry would be met with some unique challenges, due to its novelty. One of the most challenging aspects of implementing a biorefinery capable of realizing PHA production as suggested by Wellisch et al. is achieving an effective and appropriate infrastructure with viable economics (2010). Both Wellisch et al. and Narayan emphasize that production of the raw products, regardless of efficiency, has no purpose without proper facilities that can utilize the materials $(2010 ; 2006)$. Currently, there is a huge insufficiency of these facilities, even though various biodegradable products are available to consumers (J-Trend Systems, Inc., 2013; Biodegradable Food Services, Inc., 2012). The infrastructure challenge has been encountered and overcome by the biofuel sector and thus could serve as a model for the bioplastics industry (Hannon et al., 2010).

Ideally, a biorefinery would be built next to existing power plants to facilitate cogeneration of various energy sources and bioproducts while approaching 100\% sustainability. It would mimic the format of the conventional petroleum industry, attributing $~ 90 \%$ of raw biomass to fuel sources and $\sim 10 \%$ to plastics. This would mandate the cooperation and adjustments by economic, social, agricultural, and environmental sectors (Wellisch, 2010). The biorefinery created would be defined by yet more inputs, such as the availability of know-how, feedstocks, investment, as well as existing facilities, government policies, and public acceptance of the entire process. Shivley stresses that the cooperation of people across different sectors is critical and asserts there is a crucial need for starting a completely new infrastructure, as current landfills are so contaminated with petroleum plastic that they are inert with too little microbial activity, rendering their full recovery impossible (2006).

In spite of these challenges, several bio-based and biodegradable plastics have reached industry scale and are available to consumers. BASF has introduced two biodegradable plastics, ecoflex ${ }^{\circledR}$ and ecovio ${ }^{\circledR}$; one is totally petroleum based, and one is a combination of petroleum and plant starch-derived (BASF, 2010). Other encouraging evidence includes substantial investments in Canadian bioplastic technology licensing, Nestle's sugar cane-derived polyethylene packaging, increased partnerships in North American bioplastic start-ups, and growth in Europe's bioplastic packaging industry (Roberts, 2013).

The PHA bioplastic industry, specifically, has recently moved beyond the proof-of-concept phase; Metabolix ${ }^{\circledR}$, a European-based bioscience engineering company, has successfully launched a bio-based PHA production program (Metabolix, 2013a). The platform optimizes multi-gene expression techniques to maximize the PHB content of not only switchgrass, but camelina (high oil yields) and sugarcane (high biomass yields), and the company states there are more than 30 current platforms within the company related to renewable crops with novel purpose (Metabolix, 2013b).

Another issue related to bioplastics is simply in language; this aspect is too often overlooked. A uniform, internationally-recognized set of definitions is needed to enable the distinction of "bioplastic" (or, biopolymer), "biobased," and "biodegradable." The widespread abuse of the "bio-" prefix adds another level of complexity to any discussion and a stated message often betrays its intent. To date, there are few strict, legally protected definitions under the "bio" distinction. Different sources may assume contradicting definitions for the various terms, although some international not-for-profit organizations exist in attempt to maintain plastic compostable or biodegradable standards conveyed by specific logos (Biodegradable Products Institute, 2012; Bureau de normalization du Québec, 2014; ASTM International, 2003). An example of 
misconstrued concepts can be found at the Ontario Ministry of Agriculture and Food website; it declares that "Bioplastics are polymers produced from starch crops ... and vegetable oils," then simply generalizes that "Bioplastics are biodegradable" (2013). This oversimplification is misleading; for example, polyethylene and nylon 11 are not biodegradable, despite their original bio-based source (Tokiwa et al., 2009). In reality, both biodegradable and bio-based plastics are different types of bioplastics as both originate from organic material, but such a generalized view of bioplastics is problematic since it implies all plastics originating from bio-based sources are biodegradable, while all petroleum-based plastics are not. Biodegradable plastics include some petroleum (for example, polycaprolactone and poly(butylene succinate)) as well as some biomass-based; non-biodegradable plastics can include petroleum and some biomass-based, yet all may fall under the bioplastic designation (Tokiwa et al., 2009).

What is more, different derivatives of the same compound may determine whether or not it is "biodegradable," or the definition may change under certain circumstances. For example, the degree to which bio-based acetyl cellulose is acetylated determines its susceptibility to degradation (Tokiwa et al., 2009). Finally, the conditions which are available (or not) to degrade the waste will determine its utility as a biodegradable compound. Before the infrastructure is established, it is beneficial to find the most ideal bio-based, biodegradable compound; this pursuit must begin at the molecular level. Several ideal candidates have been identified as potential bioplastic sources to date, each with unique properties as previously described (Tokiwa et al., 2009).

\section{Future Outlooks}

In theory, the PHA bioplastic integration technology is reasonable. Of course, there are benefits and challenges in any new technology, and consequently those involved with the industry's inception must be prepared for these hurdles. To sustain PHA as a value-added product, it must be produced in a large enough scale to be accepted as a material for targeted markets, be achievable biologically, and have a realistic production scenario. But these scenarios are still largely theoretical. Proper combination of in vivo sites of PHA production, ideal host, and ideal growing location for the host increases the complexity of the situation. Moreover, the likelihood of PHA as a realistic bioplastic can be viewed as location-dependent geographically, in terms of infrastructure, or genetically, as it pertains to PHA production in the host organism's system. Bacterial cells can prove resilient in the process of cell lysis preceding PHA extraction. Enzymatic treatments are complex and expensive, and are not realistic for industrial-scale efficiency requirements at this time (Narayan, 2006). Prokaryotic and archaea hosts require sterile, in vitro growing environments and also proper external carbon sources. PHA processes are much more environmentally-dependent due to their occurrence in living organisms. Extraction processes result in a very viscous polymer solution, which can be challenging to transport in-house or can complicate and slow processing equipment. Furthermore, solvents necessary for the processes can be dangerous, and they are from nonsustainable sources which conflicts with the overall goal of sustainability of the production of a bioplastic. Extractions can result in damage to residual material that could have potential for value-added co-products. Non-natural producers of PHA with the inserted genes required for PHA production may become unstable and, if PHA levels exceed $8 \%$ dwt, deleterious effects may result (Suriyamongkol et al., 2007; Narayan, 2006). Large scale shift to Switchgrass crops may influence soil and water use and thus obligate changes to current land management practices (Shively, 2006). To date, PHA production costs are 5 to 10 -fold higher than those of petroleum plastics (Suriyamongkol et al., 2007). Underlying all these challenges is the difficulty of public acceptance of another large-scale, non-food GM crop, or at least enabling a forum for unbiased, educated discussion of the general topic of GM.

And still, many positive changes would be achieved in shifting to bioplastics. PHA can be obtained from many sources. PHA has no known harmful effects on animals and has a net-neutral effect on carbon cycles while reducing GHG emissions. PHA can directly substitute petroleum plastics and would enhance the biotechnology industry in Canada. There are few to no disposal costs of PHA. Cellulosic material is the most abundant carbon source on the planet, with the United States alone having a potential for 390 million tons of dedicated feedstocks (Snell \& Peoples, 2009). Development of PHA-rich crops is ideal for Canadian producers for both climate and management practices. Currently used PHA-producing plant strains require few management practice changes and PHA accumulations have been achieved in vivo. Risk of Switchgrass out-competing and dominating natural vegetation or contemporary crops is low due to its mechanisms of focusing on root mass for survival in poor soils, rather than energy inputs into reproduction (McLaughlin \& Kszos, 2005). 50\% of solid waste in landfills is biowaste, and its degradation will increase soil value (Snell \& Peoples, 2009). About 10\% dry residual material remains after PHA extraction and can be used for energy/fuel sources for the recovery process in the biorefinery, with excess going into the main power grid (UN-Energy, 2007). Thus, biorefineries have the potential to reach nearly $100 \%$ sustainability. Harvesting of plant 
biomass would also be accomplished using conventional equipment and techniques, would build on pre-existing knowledge of farmers, and offer another option for crop rotations.

\section{Conclusion}

There will be a learning period in optimizing the large-scale industrialization of PHA bioplastics to replace or enhance petroleum plastics, but the attainable long-term advantages suggest that these barriers are the means to a justified end. There are many health, environmental, and industrial benefits to gain by successfully implementing the bioplastic industry when compared to the current petroleum plastic industry and potential petroleum crises. It may be necessary to refine and establish more approachable vernacular regarding the bioproduct and bioplastic industry to allow discussion of the topic to be commonplace, and thus increase potential for public acceptance. A solid basis of understanding the science of PHA bioplastic is established and has moved beyond proof of concept, but more research and development is crucial. Once raw material production is optimized, a fundamental shift of thinking of all sectors should be welcomed. PHA bioplastic production is an encouraging industry with much potential for innovative contributions in agriculture and technology, and to the economy of Saskatchewan and the world.

\section{Acknowledgements}

I would like to thank Dr. Xiao Qiu for consultation during the research of this review, Dr. George G. Khachatourians and Dr. Bill Roesler for their feedback during the editing process, as well as the insight of the authors of the works referred to in this review. Molecular structures were generated using eMolecules online tools.

\section{References}

American Association of Petroleum Geologists. (2012). What is petroleum? Retrieved from http://www.aapg.org/about/petroleumgeology/petroleum-through-time/what-is-petroleum

Arian, R. (2013, October 9). A brief history of oil prices and Middle East tensions: Fear of a black gold shortage. Retrieved from http://www.pennenergy.com/articles/pennenergy/2013/ 10/a-brief-history-of-oil-prices-and-middle-easttensions-fear-of-a-black-gold-shortage.html
ASTM International. (2003). Specification for biodegradable plastics used as coatings on paper and other compostable substrates. doi:10.1520/D6868-03

Baptist, J.N. (1962). Patent \# USo03044942. United States Patent Office. Retrieved from http://patft.uspto.gov/netahtml/PTO/srchnum.htm

BASF. (2010). Introduction to biodegradable plastics. Retrieved from http://www.bioplastics.basf.com

Bienkowski, B. (2013, February 19). UN, WHO panel calls hormone-disrupting chemicals a 'global threat'. Environmental Health News. Retrieved from http://www.environmentalhealthnews.org/ehs/news/20 13/who-report

Biodegradable Food Services. (2012). TaterWare. Retrieved from http://www.earth-to-

go.com/index.php?option=com_content\&view=article\&i $\mathrm{d}=105$ \& $\mid$ temid $=172$

Biodegradable Products Institute. (2012). ASTM D6400 Test for Compostability. Retrieved from http://www.bpiworld.org/Default.aspx?pageld=190422

Bureau de normalisation du Québec. (2014). Home page. Retrieved from http://www.bnq.qc.ca/en/

Butt, N., Beyer, H.L., Bennett, J.R., Biggs, D., Maggini, R., Mills, M., Renwick, A.R., Seabrook, L.M.,\& Possingham, H.P. (2013). Biodiversity risks from fossil fuel extraction. Science, 342(6157), 425-426. doi:10.1126/science.1237261

Canadian Association of Petroleum Producers. (2014). Glossary. Retrieved from http://www.capp.ca/library/glossary/Pages/default.aspx $\# p$

Canadian Plastics Industry Association. (2010). Industry profile. Retrieved from http://www.plastics.ca/IndustryProfile/index.php

Chemical Heritage Foundation. (2010). Science of plastics. Retrieved from http://www.chemheritage.org/discover/onlineresources/conflicts-in-chemistry/the-case-of-plastics/allscience-of-plastics.aspx

Chowdhury, A.A. (1963). Poly- $\beta$-hydroxybuttersaure abbauende Bakterien und exo-enzyme. Archives of Microbiology, 47, 167-200. doi:10.1007/BFoo422523

Foreign Affairs, Trade and Development Canada. (2013). Harper government highlights importance of foreign direct investment to chemicals and plastics industries. Retrieved from http://www.international.gc.ca/media/comm/newscommuniques/2013/12/11b.aspx?lang=eng

Forni, D., Wenk, C., \& Bee, G. (1999a). Digestive utilization of novel biodegradable plastic in growing pigs. Annales de Zootechnie 48: 163-171. doi:10.1051/animres:19990302. 
Forni, D., Wenk, C., \& Bee, G. (1999b). Novel biodegradable plastics in sheep nutrition 1. Effects of untreated plastics on digestibility and metabolic energy and nitrogen utilization. Journal of Animal Physiology and Animal Nutrition, 81:31-40. doi:10.1046/j.14390396.1999.811189.x

Government of Saskatchewan. (2009). Crops. Retrieved from http://www.agriculture.gov.sk.ca/crops

Hannon, M., Gimpel, J., Tran, M., Rasala, B., \& Mayfield, S. (2010). Biofuels from algae: Challenges and potential. Biofuels. 1(5):763-784. PMCID: PMC3152439

Houmiel, K.L., Slater, S., Broyles, D., Casagrande, L., Colburn, S., Gonzalez, K., Mitsky, T.A., Reiser, S.E., Shah, D., Taylor, N.B., Tran, M., Valentin, H.E., \& Gruys, K.J. (1999). Poly( $\beta$-hydroxybutyrate) production in oilseed leukoplasts of Brassica napus. Planta, (209)4, 547-550. doi:10.1007/s004250050760

Huang, J., Pray, C., \& Rozelle, S. (2002). Enhancing the crops to feed the poor. Nature, 418(6898), 678-685. doi:10.1038/nature01015

Huang, R., \& Reusch, R.N. (1996). Poly(3-hydroxybutyrate) is associated with specific proteins in the cytoplasm and membranes of Escherichia coli. Journal of Biological Chemistry, 271(36), 22196-202. doi:10.1074/jbc.271.36.22196

Hutton, A., Bharati, S., \& Robl, T. (1994). Chemical and Petrographic Classification of Kerogen/Macerals. Energy Fuels, 8(6), 1478-1488. doi:10.1021/efooo48ao38

International Energy Agency. (2012). Oil: Medium-Term Market Report 2012. Retrieved from http://www.iea.org/publications/freepublications/public ation/MTOMR2012WEB.pdf

International Energy Agency. (2013). FAQs: Oil. Retrieved from http://www.iea.org/aboutus/faqs/oil/

IUPAC. (1997). Compendium of Chemical Terminology (2nd ed.). Compiled by A.D. McNaught and A. Wilkinson. Oxford: Blackwell Scientific.

J-Trend Systems. (2013). jtrend-systems ${ }^{\mathrm{TM}}$ green initiatives in cleaning and protecting the environment through green purchasing of everyday green products in every walk of life. Retrieved from http://www.degradableplasticbag.com/go-greenprograms/index.html

Klare, M.T. (2007, Nov 12). Beyond the age of petroleum. The Nation. Retrieved from http://www.thenation.com/article/beyond-agepetroleum\#

Kunasundari, B., \& Sudesh, K. (2011). Isolation and recovery of microbial polyhydroxyalkanoates. eXPRESS Polymer Letters, 5(7), 620-634. doi:10.3144/expresspolymlett.2011.6o
Lemoigne, M. (1926). Produits de dehydration et de polymerisation de l'acide $\beta$-oxobutyrique. Bulletin de la Societe de Chimie Biologique, 8, 770-82.

Lodish, H., Berk, A., Zipursky, S.L., Matsudaira, P., Baltimore, D., \& Darnell, J. (2000). Noncovalent bonds. In Molecular cell biology (4th ed.). Retrieved from http://www.ncbi.nlm.nih.gov/books/NBK21726/

McLaughlin, S.B., \& Kszos, L.A. (2005). Development of switchgrass (Panicum virgatum) as a bioenergy feedstock in the United States. Biomass and Bioenergy, 28(6), 515-535. doi:http://dx.doi.org/10.1016/j.biombioe.2004.05.006

Metabolix. (2008). Metabolix demonstrates viability of bioplastic production in switchgrass plants. Retrieved from http://ir.metabolix.com/releasedetail.cfm?ReleaselD=32 7506

Metabolix. (2013a). Why integrate biopolymers into your conversion process? Retrieved from http://www.metabolix.com/converters

Metabolix. (2013b). Crop-based technologies. Retrieved from http://www.metabolix.com/Products/Crop-basedTechnologies

Narayan, R (2006). Biobased and biodegradable polymer materials: Rationale, drivers, and technology exemplars. In K. Khemani \& C. Scholz (Eds.), Degradable polymers and materials: Principles and practice (pp. 282-306). Washington, DC: American Chemical Society.

National Aeronautics and Space Administration. (2014a). Climate change: How do we know? Retrieved from http://climate.nasa.gov/evidence

National Aeronautics and Space Administration. (2014b). A blanket around the Earth. Retrieved from http://climate.nasa.gov/causes

NewsRX (2013, March 5). "Chemically inducible expression of biosynthetic pathways" in patent application approval process. Life Science Weekly. Retrieved from http://www.highbeam.com/doc/1G1-323547527.html

Ontario Ministry of Agriculture and Food. (2013). Introduction to Bioproducts. Retrieved from http://www.omafra.gov.on.ca/english/crops/facts/10o13w.htm

Organization of the Petroleum Exporting Countries. (2014). OPEC Share of World Crude Oil Reserves 2012. Retrieved from http://www.opec.org/opec_web/en/data_graphs/330.ht $\mathrm{m}$

Parkash, S. (2010). Petroleum fuels manufacturing handbook: Including specialty products and sustainable manufacturing techniques. New York, NY: McGraw-Hill.

PlasticsEurope. (2013a). How plastic is made. Retrieved from http://www.plasticseurope.org/what-is-plastic/howplastic-is-made.aspx 
PlasticsEurope. (2013b). First estimates suggest around $4 \%$ increase in plastics global production from 2010.

Retrieved from

http://www.plasticseurope.org/information-

centre/press-room-1351/press-releases-2012/firstestimates-suggest-around-4-increase-in-plastics-globalproduction-from-2010.aspx

Rapier, R. (2014). Setting the record straight on U.S. oil reserves. Retrieved from http://www.energytrendsinsider.com/2012/03/26/settin g-the-record-straight-on-u-s-oil-reserves/

Reddy, C.S., Ghai, R., Rashmi, \& Kalia, V.C. (2003). Polyhydroxyalkanoates: An overview. Bioresource Technology, 87(2), 137-46. doi:10.1016/Sog6o$8524(02) 00212-2$

Redekop, B. (2006). The 'oil' of the prairies. Winnipeg Free Press.

Rehm, B.H. (2003). Polyester synthases: Natural catalysts for plastics. Biochemical Journal, 376, 15-33. doi: 10.1042/BJ20031254

Roberts, O. (2013). Canadian bio-plastic sets up for agriinnovation. Retrieved from https://www.fccfac.ca/en/ag-knowledge/publications/fcc-express/fccexpress-archives/20130607.html\#Story 7

Rudolf, J.F. (2014). Less than 50 years of oil left, HSBC warns. Retrieved from http://green.blogs.nytimes.com/2011/03/30/less-than50-years-of-oil-left-hsbcwarns/?_php=true\&_type $=$ blogs \&_r=0

Shivley, J.M. (2006). Preface. In J.M. Shivley (Eds.), Inclusions in Prokaryotes. Berlin Heidelberg: SpringerVerlag.

Smet, M.J., Eggink, G., Witholt, B., Kingma, K., \& Wynberg, H. (1983). Characterization of intracellular inclusions formed by Pseudomonas oleovorans during growth on octane. J. Bacteriol, 154(2), 870-878. Retrieved from http://www.ncbi.nlm.nih.gov/pmc/articles/PMC217541/

Snell, K.D., \& Peoples, O.P. (2009). PHA Bioplastic: A valueadded coproduct for biomass biorefineries. Biofuels, Bioproducts \& Biorefining, 3(4), 456-467. doi:10.1002/bbb.161

Somleva, M.N., Snell, K.D., Beaulieu, J.J., Peoples, O.P., Garrison, B.R., \& Patterson, N.A. (2008). Production of polyhydroxybutyrate in switchgrass, a value-added coproduct in an important lignocellulosic biomass crop. Plant Biotechnology Journal, 6(7), 663-78. doi:10.1111/j.1467-7652.2008.00350.x

Sticklen, M. (2008). Plant genetic engineering for biofuel production: Towards affordable cellulosic ethanol. Nature Reviews Genetics, 9(6), 433-443. doi:10.1038/nrg2336
Sudesh, K., Abe, H., \& Doi, Y. (2000). Synthesis, structure and properties of polyhydroxyalkanoates: Biological polyesters. Progress in Polymer Science, 25(10), 15031555 .

Suriyamongkol, P., Weselake, R., Narine, S., Moloney, M., \& Shah, S. (2007). Biotechnological approaches for the production of polyhydroxyalkanoates in microorganisms and plants-A review. Biotechnology Advances, 25(2), 148-175. doi: http://dx.doi.org/10.1016/j.biotechadv.2006.11.007

Tokiwa, Y., Calabia, B.P., Ugwu, C.U., \& Aiba, S. (2009). Biodegradability of plastics. International Journal of Molecular Sciences, 10(9), 3722-3742. doi:10.3390/ijms10093722

Torrente, M.C., \& Galán, M.A. (2011). Extraction of kerogen from oil shale (Puertollano, Spain) with supercritical toluene and methanol mixtures. Industrial \& Engineering Chemistry Research, 50(3), 1730-1738. doi:10.1021/ie1004509

Traore, N. (2003). Bioproducts development by Canadian biotechnology firms: Findings from the 2001 Biotechnology Use and Development Survey. Retrieved from http://www.oecd.org/science/biotech/34339418.pdf

U.S. Department of Energy. (2013a). How fossil fuels were formed. Retrieved from http://www.fe.doe.gov/education/energylessons/coal/ge n_howformed.html

U.S. Department of Energy. (2013b). Total petroleum consumption (thousand barrels per day). Retrieved from http://www.eia.gov/cfapps/ipdbproject/iedindex3.cfm?ti $\mathrm{d}=5$ \& pid $=5$ \&aid $=2 \&$ cid $=$ regions $\&$ syid $=1980 \&$ eyid $=2010$ \&unit=TBPD

U.S. Energy Information Administration. (2013). International energy outlook 2013. Retrieved from http://www.eia.gov/forecasts/ieo/pdf/0484(2013).pdf

UN-Energy. (2007). Sustainable Bioenergy: A framework for decision makers. Retrieved from http://www.fao.org/docrep/010/a1094e/a1094eoo.htm

United States Environmental Protection Agency. (2010). Waste and cleanup risk assessment. Retrieved from http://www.epa.gov/oswer/riskassessment/glossary.htm

United States Environmental Protection Agency. (2013). Types of crude oil. Retrieved from http://www2.epa.gov/emergency-response/typescrude-oil

van Veilen, J.B., \& Poirier, Y. (2008). Production of renewable polymers from crop plants. The Plant Journal, 54, 684-701. doi:10.1111/j.1365-313X.2008.03431.X

Wellisch, M., Jungmeier, G., Karbowski, A., Patel, M.K., \& Rogulska, M. (2010). Biorefinery systems - potential contributors to sustainable innovation. Biofuels, Bioproducts \& Biorefining, 4(3), 275-286. DOI: 10.1002/bbb.217 
Wiehe, I.A. (2008). Introduction to the processing of petroleum macromolecules. In Process Chemistry of Petroleum Macromolecules. Boca Raton, FL: CRC Press.

Williamson, D.H., \& Wilkinson, J.F. (1958). The isolation and estimation of the poly-beta-hydroxybutyrate inclusions of Bacillus species. Journal of General Microbiology, 19(1), 198-209. doi: 10.1099/00221287-19-1-198. 